\title{
Dioxomolybdenum(VI) compounds with $\alpha$-amino acid donor ligands as catalytic precursors for the selective oxyfunctionalization of olefins
}

\author{
Issam Abdalghani, ${ }^{a}$ Lorenzo Biancalana, ${ }^{b, c}$ Massimiliano Aschi, ${ }^{a}$ Guido Pampaloni, ${ }^{\text {b,c }}$ Fabio \\ Marchetti, ${ }^{\mathrm{b}, \mathrm{c}, *}$ Marcello Crucianelli ${ }^{\mathrm{a}}{ }^{*}$ \\ ${ }^{a}$ Department of Physical and Chemical Sciences, University of L'Aquila, via Vetoio, I-67100 L'Aquila, Italy \\ ${ }^{b}$ Department of Chemistry and Industrial Chemistry, University of Pisa, via G. Moruzzi 13, I-56124 Pisa, Italy \\ ${ }^{\mathrm{c}}$ IRCC, via Celso Ulpiani 27, I-70126 Bari, Italy.
}

\begin{abstract}
A series of cis-dioxomolybdenum(VI) $\alpha$-amino acid containing compounds I-V has been investigated as potential catalyst precursors for the mild and selective oxyfunctionalization of conjugated or unconjugated olefins like styrene, $\alpha$-methylstyrene, $\operatorname{cis}$ - $\beta$-methylstyrene, cyclohexene and cyclooctene, using tert-butyl hydroperoxide (TBHP) as main oxidant. All the I-V complexes behaved as active heterogeneous and recyclable catalysts, showing good to quantitative conversion values of the substrate. In all cases, high selectivity toward the corresponding epoxide formation was detected. No substantial difference in terms of efficiency has been observed among the different catalysts $\mathbf{I}-\mathbf{V}$, thus confirming that the different nature of the amino acidic side-chain does not strictly affect the catalytic process. Insights into mechanistic details and reaction free energy profile of catalytic oxidations by means of quantum chemical calculations have been discussed.
\end{abstract}

Keywords: cis-dioxomolybdenum; $\alpha$-amino acid; olefin oxidation; heterogeneous catalysis; tert-butyl hydroperoxide

*Corresponding authors: Tel.: (+39) 050-2219245; e-mail: fabio.marchetti1974@unipi.it (F. Marchetti).Tel.: (+39) 0862-433308; e-mail: marcello.crucianelli@univaq.it (M. Crucianelli)

\section{Introduction}

Molybdenum occurs in a wide range of metalloenzymes covering key positions both in biochemical cycles of carbon, nitrogen and sulfur and in the metabolism of living organisms [1]; its very rich redox 
chemistry might explain why it is the only member of the second transition series with known biological functions [2]. In this context, the tremendous impetus arisen in the synthesis of a number of model complexes mimicking oxotransferase molybdoenzymes is not surprising [3], finding application in catalytic oxygen atom transfer (OAT) reactions [4]. Since many years, catalytic oxidation has established to be a key technology for converting petroleum feedstocks into useful chemicals such as alcohols, carbonyl compounds and epoxides.

Epoxides are, in turn, important synthetic intermediates for the synthesis of oxygen containing derivatives. Styrene oxide and benzaldehyde are among the most important products obtained from the catalytic oxidation of styrene. Benzaldehyde is a very valuable chemical that has widespread application in perfumery, pharmaceuticals, dyestuffs, and agrochemicals; it is the second most important aromatic molecule (after vanillin) used in the cosmetics and flavor industries [5]. On the other hand, styrene oxide can be used for producing epoxy resin diluting agents, ultraviolet absorbents, flavoring agents, etc., and it is also an important intermediate for organic synthesis, pharmacochemistry and perfumery [6].

In the light to develop sustainable catalytic processes based on non toxic metal species, molybdenum appears a good choice. In particular, Mo(VI) compounds are able to activate mild oxidants such as $\mathrm{H}_{2} \mathrm{O}_{2}$, alkyl hydroperoxides or air, thus overcoming the severe environmental and health restrictions connected to the use of peracids [7]. Especially, molybdenum(VI) dioxo species are highly active and selective in the epoxidation of internal aliphatic alkenes (e.g. cyclooctene or cyclohexene) [7a, 8], while the epoxidation of terminal alkenes (e.g. styrene) remains challenging, because frequently the formation of ring-opening products comes favoured [9]. As a matter of fact, only a limited number of effective molybdenum(VI) dioxo complexes have appeared in the literature as effective catalysts for styrene epoxidation [10].

The study of the interaction between molybdenum compounds and naturally-occurring molecules is intended to contribute to the coordination chemistry of Mo(VI), particularly in water, and everything that ensues from it for catalytic purposes. In this respect, $\alpha$-amino acids are attracting ligands due to easy availability, low toxicity and the usual presence of an asymmetric centre, and indeed their coordination to a variety of metal ions has been extensively investigated [11]. The chemistry of oxomolybdenum (V) [12] or Mo(VI) species with $\alpha$-amino acids in aqueous medium has aroused huge interest, as witnessed by several publications [13]. In spite of this, only sparse information have appeared in the literature on the use of $\mathrm{Mo}(\mathrm{VI})$-amino acid compounds in the oxidative derivatization of synthetically important olefins [14]. Some of us, recently described a detailed solid-state 
characterization of a series of poorly soluble $\mathrm{Mo}(\mathrm{VI})$ compounds isolated after the reaction of molybdate salts with $\alpha$-amino acids from acidic aqueous solutions [15]. Solid-state IR and NMR spectroscopy, corroborated by DFT studies, indicated the formation of polymeric species of general formula $\left\{\mathrm{Mo}_{2} \mathrm{O}_{5}(\mathrm{OH})_{2}(\alpha \text {-amino acid })\right\}_{\mathrm{n}}$ whose repeating unit featured cis $-\mathrm{MoO}_{2}$ fragment bridged by a zwitterionic bidentate $\alpha$-amino acid donor ligand (see Chart 1).

Herein we describe a study on these Mo(VI) $\alpha$-amino acid complexes I-V (Chart 1) as potential catalysts for the mild and selective catalytic oxyfunctionalization of conjugated or unconjugated olefins (styrene, $\alpha$-methylstyrene, cis- $\beta$-methylstyrene, cyclohexene and cyclooctene), using tert-butyl hydroperoxide (TBHP) as oxygen source. The results of quantum chemical calculations will be discussed to give insights into mechanistic and thermodynamic aspects.

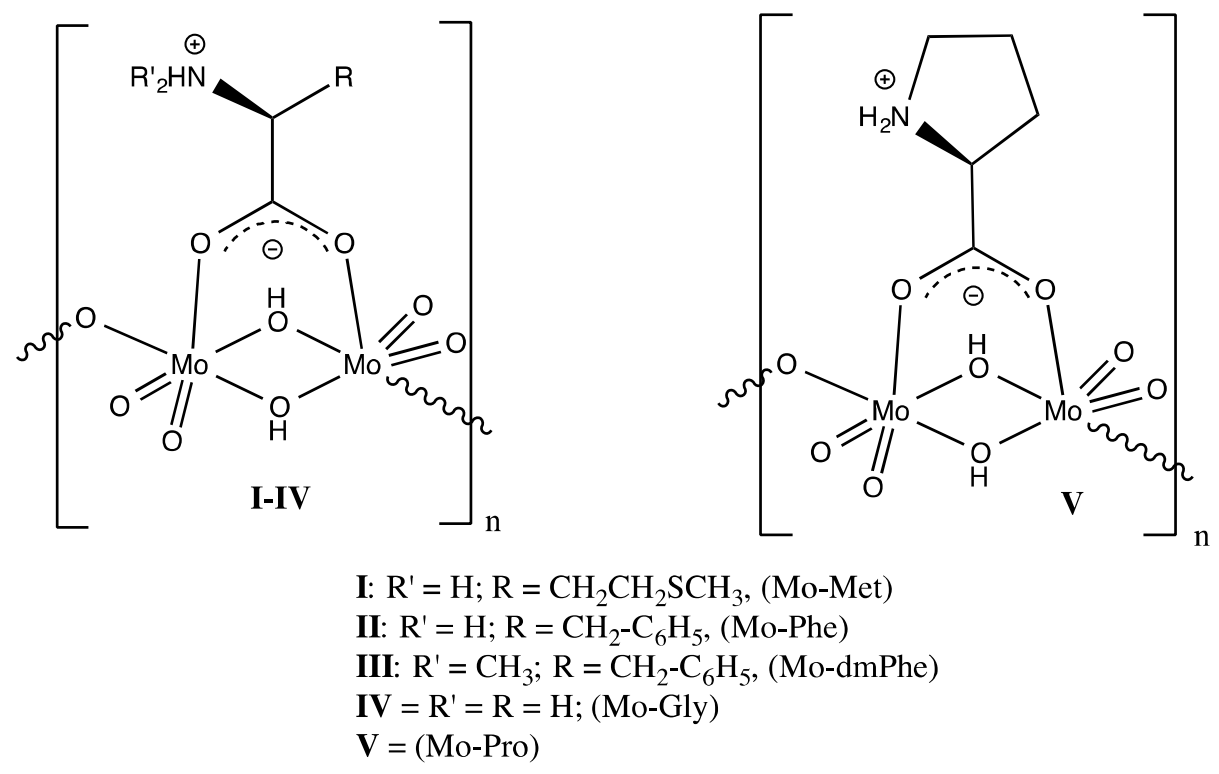

Chart 1. Molybdenum(VI) complexes, with L-Methionine (I), L-Phenylalanine (II), N,N-dimethyl-LPhenylalanine (III), Glycine (IV) and L-Proline (V) as $\alpha$-amino acid ligands.

\section{Experimental Section}

\section{Materials and methods}

All reagents and solvents were purchased from Sigma-Aldrich (Italy) in the highest purity grade available and were used as such. A $5.5 \mathrm{M}$ solution in $n$-decane (or $70 \% \mathrm{w} / \mathrm{w}$ aqueous solution) of tert- 
butyl hydroperoxide (TBHP), or a $35 \% \mathrm{w} / \mathrm{w}$ aqueous solution of $\mathrm{H}_{2} \mathrm{O}_{2}$, were used as primary oxidants. Compounds I-V were prepared according to the literature [15]. Molar concentrations of aqueous solutions of, respectively, $70 \% w / w$ of TBHP and $35 \% w / w$ of $\mathrm{H}_{2} \mathrm{O}_{2}$, were determined via ${ }^{1} \mathrm{H}$ NMR using $\mathrm{Me}_{2} \mathrm{SO}_{2}$ as internal standard, in $\mathrm{D}_{2} \mathrm{O}$ solution $\left[\delta=3.05\left(\mathrm{Me}_{2} \mathrm{SO}_{2}\right), 1.15\right.$ (TBHP) ppm] (for TBHP) or THF solution $\left[\delta=9.59\left(\mathrm{H}_{2} \mathrm{O}_{2}\right), 3.09\left(\mathrm{Me}_{2} \mathrm{SO}_{2}\right) \mathrm{ppm}\right.$ ] (for $\left.\mathrm{H}_{2} \mathrm{O}_{2}\right)$. NMR spectra were recorded at 298 $\mathrm{K}$, respectively, on a Bruker Avance II DRX400 equipped with a BBFO broadband probe, or with a Bruker Avance III $400 \mathrm{MHz}$ instruments. Solid-state infrared spectra were recorded on a Perkin Elmer Spectrum One FT-IR spectrometer, equipped with a UATR sampling accessory. Infrared spectra of $\mathrm{CDCl}_{3}$ solutions were recorded on a Perkin Elmer Spectrum 100 FT-IR spectrometer with a $\mathrm{CaF}_{2}$ liquid transmission cell in the $4000-1000 \mathrm{~cm}^{-1}$ range. UV-Vis spectra were recorded on a Ultraspec 2100 Pro spectrophotometer with $0.1 \mathrm{~cm}$ quartz cuvettes in the 190-900 $\mathrm{nm}$ range. Gas chromatographic analyses (GC-FID) were performed by means of a Hewlett-Packard 6890 series instrument equipped with a flame ionization detector, using a $30 \mathrm{~m} \times 0.32 \mathrm{~mm} \times 0.25 \mu \mathrm{m}$ film thickness (crosslinked $5 \%$ phenylmethylsiloxane) column and chromatography grade helium, as carrier gas. In GC calculations, all peaks amounting to at least $0.5 \%$ of the total products were considered. ${ }^{1} \mathrm{H}$ and ${ }^{13} \mathrm{C}$ NMR analyses of products were performed after purification, and compared with authentic samples. Mass spectra were recorded with an electron beam of $70 \mathrm{eV}$.

\section{Catalytic oxidations}

All catalytic experiments were carried out in a carousel reactor fitted with a water condenser. In a typical experiment, $2 \cdot 10^{-3} \mathrm{mmol}(1.0 \mathrm{~mol} \%$ vs. olefin) of the selected catalyst was suspended in 1.0 $\mathrm{mL}$ of chloroform and $0.4 \mathrm{mmol}$ (2.0 equivalents vs. olefin) of TBHP (5.5 $\mathrm{M}$ in $n$-decane) were added, followed by $0.2 \mathrm{mmol}$ of the selected olefin. The reaction mixture was stirred at $50{ }^{\circ} \mathrm{C}$ for the chosen time and the reaction progress was monitored and evaluated by GC analysis by taking, at regular time intervals, aliquots of the crude. $n$-Hexadecane or mesitylene (in the case of cyclohexene or cyclooctene, respectively) were used as internal standard. At the end of reaction, the mixture was quenched with 1.0 $\mathrm{mL}$ of a $5 \%$ aqueous solution of $\mathrm{Na}_{2} \mathrm{~S}_{2} \mathrm{O}_{5}$ and the organic phase recovered with $1.0 \mathrm{~mL}$ of chloroform, dried over anhydrous $\mathrm{MgSO}_{4}$ and analyzed by $\mathrm{GC}$.

Reactivity of compound I with $\mathrm{H}_{2} \mathrm{O}_{2}$ or TBHP.

General procedure: compound I $\left[\mathrm{Mo}_{2} \mathrm{O}_{4}(\mathrm{OH})_{4}(\mathrm{Met})\right]\left(19 \mathrm{mg}, 4 \cdot 10^{-2} \mathrm{mmol}\right), \mathrm{CDCl}_{3}(4.0 \mathrm{~mL}), \mathrm{PhNO}_{2}$ $\left(5.0 \mu \mathrm{L}, 4.9 \cdot 10^{-2} \mathrm{mmol}\right)$ as NMR internal standard and the selected oxidant ( $c a .200$ eq.) were 
introduced in a test tube. The reaction mixture, equipped with a reflux condenser, was stirred for 4 hours at $50{ }^{\circ} \mathrm{C}$. The organic phase was periodically sampled $(\mathrm{t}=0,1,2$, and 3 hours $)$ for IR, ${ }^{1} \mathrm{H}$ NMR and UV-Vis analysis (see below), showing no evidence for the formation of a soluble Mo-methionine species. Then, molybdenum-containing compounds I-A and I-B were isolated as described below.

Compound $\mathbf{I}$ and $\mathrm{H}_{2} \mathrm{O}_{2}$ : organic phase monitoring and isolation of $\boldsymbol{I}-\boldsymbol{A}$. The reaction was performed with $35 \% w / w \mathrm{H}_{2} \mathrm{O}_{2}(0.72 \mathrm{~mL}, 8.03 \mathrm{mmol})$. Reaction mixture $(1-3 \mathrm{~h})$ : yellow aqueous solution $\left(\lambda_{\max }=\right.$ $307 \mathrm{~nm}) /$ colorless organic solution. ${ }^{1} \mathrm{H}$ NMR $\left(\mathrm{CDCl}_{3}\right): \mathrm{H}_{2} \mathrm{O}(\delta=1.60 \mathrm{ppm})$ and $\mathrm{H}_{2} \mathrm{O}_{2}(\delta=5.88-5.26$ ppm [16a]) signals were identified. IR $\left(\mathrm{CDCl}_{3}\right)$ : variations due to $\mathrm{H}_{2} \mathrm{O} / \mathrm{H}_{2} \mathrm{O}_{2}$ bands (ṽ: 3600-3200br, $\left.1711,1364,1224 \mathrm{~cm}^{-1}\right)$ were observed. UV-Vis $\left(\mathrm{CDCl}_{3}\right)$ : no absorptions $\left(0-3 \mathrm{~h}, \lambda_{\text {cutoff }}=300 \mathrm{~nm}\right)$. At the end of the reaction, the aqueous phase was separated. Few mg of KI were added and the solution was stirred for $1 \mathrm{~h}$, at room temperature, to decompose excess $\mathrm{H}_{2} \mathrm{O}_{2}$. Volatiles were then removed under vacuum $\left(40^{\circ} \mathrm{C}\right)$ affording a yellow solid (I-A).

I-A: IR (solid state): $\tilde{v}\left(\mathrm{~cm}^{-1}\right)=3600-3300 \mathrm{~m}-\mathrm{br}, 3216-3160 \mathrm{~m}-\mathrm{br}, 3017 \mathrm{~m}, 2930 \mathrm{~m}, 1675 \mathrm{~m}-\mathrm{sh}, 1621 \mathrm{~m}$, $1506 \mathrm{~m}, 1444 \mathrm{~m}-\mathrm{sh}, 1405 \mathrm{~m}, 1369 \mathrm{~m}, 1323 \mathrm{~m}-\mathrm{sh}, 1281 \mathrm{~s}, 1193 \mathrm{w}, 1127 \mathrm{~s}, 1073 \mathrm{~m}, 960 \mathrm{~s}, 909 \mathrm{w}, 857 \mathrm{~s}, 805 \mathrm{w}$, $772 \mathrm{w}, 735 \mathrm{w}, 658 \mathrm{w}$.

${ }^{1} \mathrm{H}$ NMR $\left(\mathrm{D}_{2} \mathrm{O}\right): \delta=3.95(\mathrm{br}, 1 \mathrm{H}), 3.40(\mathrm{br}, 2 \mathrm{H}), 3.08(\mathrm{~s}, 3 \mathrm{H}), 2.35$ (br, 1H) ppm. ${ }^{13} \mathrm{C}\left\{{ }^{1} \mathrm{H}\right\}$ NMR $\left(\mathrm{D}_{2} \mathrm{O}\right): \delta=172.5,52.7,49.9,39.8,23.1 \mathrm{ppm}$.

Compound I-A is stable in the solid state and is soluble in acetone and water. The stability of I-A in aqueous solution without excess of $\mathrm{H}_{2} \mathrm{O}_{2}$ is limited (see Supporting Information).

Compound I and TBHP: organic phase monitoring and isolation of $\mathbf{I}-\boldsymbol{B}$. The reaction was performed with $70 \% \mathrm{w} / \mathrm{w}$ aqueous solution of TBHP $(1.06 \mathrm{~mL}, 8.01 \mathrm{mmol})$. Reaction mixture $(0-3 \mathrm{~h})$ : colorless solid dispersed in the aqueous phase/colorless organic solution. ${ }^{1} \mathrm{H}$ NMR $\left(\mathrm{CDCl}_{3}\right): \mathrm{H}_{2} \mathrm{O}(\delta=2.6-2.8$ ppm), TBHP [ $\delta=8(\mathrm{br}), 1.23(\mathrm{~s}) \mathrm{ppm}]$ and $t \mathrm{BuOH}[\delta=1.25(\mathrm{~s}) \mathrm{ppm}, \mathrm{t}=3 \mathrm{~h}]$ signals were identified. ${ }^{13} \mathrm{C}\left\{{ }^{1} \mathrm{H}\right\} \mathrm{NMR}\left(\mathrm{CDCl}_{3}\right)$ : TBHP $(\delta=80.6,25.7 \mathrm{ppm})$ and $t \mathrm{BuOH}(\delta=69.7,26.5 \mathrm{ppm}, \mathrm{t}=3 \mathrm{~h})$ were identified. IR $\left(\mathrm{CDCl}_{3}\right)$ : variations due to $t \mathrm{BuOH}$ bands $\left(\tilde{\mathrm{v}}: 3605,1149 \mathrm{~cm}^{-1}, \mathrm{t}=3 \mathrm{~h}\right)$ were observed. UV-Vis $\left(\mathrm{CDCl}_{3}\right)$ : no absorptions $\left(0-3 \mathrm{~h}, \lambda_{\text {cutoff }}=300 \mathrm{~nm}\right)$. At the end of the reaction, the suspension was filtered. The resulting colorless solid (I-B) was washed with $\mathrm{CH}_{2} \mathrm{Cl}_{2}$, acetone and dried under vacuum $\left(40{ }^{\circ} \mathrm{C}\right)$.

I-B. Yield $=15 \mathrm{mg}$. IR (solid state): $\tilde{v}=1290 \mathrm{w}, 1280 \mathrm{w}, 1125 \mathrm{w}, 809 \mathrm{w} \mathrm{cm}{ }^{-1}$ in addition to the bands of compound $\mathbf{I}$. 


\section{Computational study}

All the calculations were carried out with the Gaussian09 package RevD.01 [16b]. The structures were optimized in vacuo (fully or in the presence of constraints, see below) using a threshold of 0.008 atomic units (a.u.) for the maximum forces. Subsequently the harmonic frequencies were calculated from the eigenvalues of the mass-weighted Hessian matrix.

The frequencies and the obtained structures were then utilized for calculating gas-phase free energy at $50{ }^{\circ} \mathrm{C}$, hence mimicking the temperature of the experiment. These calculations were performed assuming a concentration of $1.0 \mathrm{M}$ for all the species taken as standard state.

The frequencies were also utilized for ascertaining the nature of the transition state (see below).

A rough estimation of the excess free energy in solution $\left(\mathrm{CHCl}_{3}\right)$ was finally carried out using Polarizable Continuum Method as implemented in the same package [17].

Note that for these calculations we utilized the dielectric constant and the cavitation free energies as obtained at $298 \mathrm{~K}$. Thus, data obtained from the calculations should be utilized at a qualitative or semiquantitative level of interpretation.

All the calculations were carried out in the framework of Density Functional Theory with the CAMB3LYP functional [18] in conjunction with 6-31G* basis set and Los Alamos Effective Core Potential in conjunction with Double Zeta basis set, LAN-L2DZ [19], for molybdenum.

Although the effect of the functional is a well assessed problem in particular when transition metals are concerned, in the present study because of the dimension of the investigated systems and the related cost of the calculations, we did not undergo a systematic sensitivity analysis.

\section{Results and Discussion}

\section{Optimization of the reaction conditions for the epoxidation of styrene with TBHP}

At the beginning, the optimal experimental conditions in terms of temperature, solvent, oxidant and catalyst loadings were evaluated by using styrene as a challenging olefin (characterized by a relatively low electron rich double bond), tert-butyl hydroperoxide (TBHP, $5.5 \mathrm{M}$ in $n$-decane) as oxidant, and catalyst I. After several preliminary experiments, the higher conversions and reaction rates achieved with $\mathrm{CHCl}_{3}$ at moderate temperatures, prompted us to select it as the best solvent for the present study, in comparison with acetonitrile or toluene. Indeed, a limited activity using coordinating solvents (e.g. 
acetonitrile) due to their ability to compete with TBHP for the binding to the Mo center, was previously described [20] and also observed in our case during the oxidation of styrene (about $30-35 \%$ of substrate conversion, at $60{ }^{\circ} \mathrm{C}$, after 8 hours). Diversely, with toluene, moderate conversions of styrene (about $50-60 \%)$ were observed but only after a longer reaction time (12 hours) and at higher temperatures (80 ${ }^{\circ} \mathrm{C}$ ). Anyway, in both cases a very low selectivity toward the formation of the epoxide was observed, being benzaldehyde the main product. Concerning the optimization of the catalyst amount $(1 \mathrm{~mol} \%, 2$ mol $\%$ or $3 \mathrm{~mol} \%$ ratios), we observed an increase in the starting material (s.m.) conversion on increasing the loading ( 2 and $3 \mathrm{~mol} \%$ ), during the first hour (within the 30-35\% range); nevertheless, the conversion values reached at the end of reaction (4-8 hours) were rather comparable in all cases, thus justifying our choice to work with $1 \mathrm{~mol} \%$ of catalyst. Lower amounts $(0.5 \mathrm{~mol} \%)$ proved to be unsatisfactory due to longer reaction times required to obtain acceptable conversion values. Concerning the oxidant/starting material molar ratio, the optimal compromise, in terms of catalytic efficiency, was 2.0 equiv., since we observed that higher molar ratios (3.0 equiv.) improved the conversion only marginally, if any. By taking constant the amount of styrene $(0.2 \mathrm{mmol})$, we observed that the increase of dilution, from 1.0 to $3.0 \mathrm{~mL}$ of $\mathrm{CHCl}_{3}$, led to a gradual decrease in substrate conversion. This result may be explained on considering that, the formation of active peroxo species at the molybdenum center, upon close interaction with TBHP at the solid/liquid interface, could be less probable in more diluted solutions. Generally speaking, a reduction in the volume of solvents is appealing, when practicable, as witnessed by some recent reports on $\left[\mathrm{MoO}_{2} \mathrm{~L}\right]_{n}$ promoted oxidative catalysis in solvent free conditions [21]. Anyway, in the case of styrene oxidation, we didn't observe substantial advantages, working under solventless conditions, neither in terms of yield nor in the selectivity toward epoxide formation. Thus, we further decided to work with $1.0 \mathrm{~mL}$ of $\mathrm{CHCl}_{3}$, also for sake of safety in the handling of TBHP. The working temperature was settled at $50{ }^{\circ} \mathrm{C}$ as a right compromise: no significant advancement of both yield and conversion values was observed under refluxing $\mathrm{CHCl}_{3}$, while the kinetic of reaction, at room temperature, was rather slow.

In summary, after the optimization study, we opted for the following experimental conditions: 0.2 mmol of substrate, $1.0 \mathrm{~mL}$ of $\mathrm{CHCl}_{3}, 1.0 \mathrm{~mol} \%$ of catalyst and 2.0 equiv. of TBHP, at $50{ }^{\circ} \mathrm{C}$, in accordance with the literature for similar catalytic systems [9a, 22]. Unless otherwise specified, these conditions have been applied to all substrates, namely styrene, $\alpha$-methylstyrene, cis- $\beta$-methylstyrene, cyclohexene and cyclooctene.

We first evaluated the activity of catalysts $\mathbf{I}-\mathbf{V}$ in the oxidation of styrene and the main results are showed in Table 1 and Figure 1. The corresponding epoxide (EP), benzaldehyde (BA) and 
phenylacetaldehyde (PA) were detected as the main products (Chart 2).
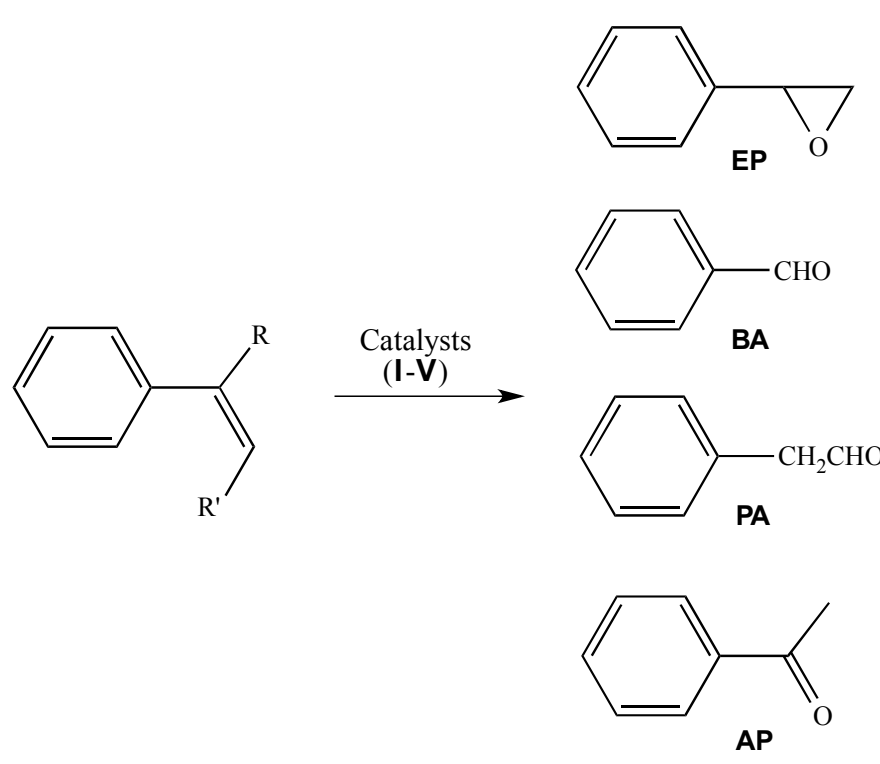

Chart 2. Graphical sketch of the main oxidation products detected in the oxidation of styrene $\left(R=R^{\prime}=\right.$ $\mathrm{H})$, $\alpha$-methylstyrene $\left(\mathrm{R}=\mathrm{CH}_{3}, \mathrm{R}^{\prime}=\mathrm{H}\right)$ and cis- $\beta$-methylstyrene $\left(\mathrm{R}=\mathrm{H}, \mathrm{R}^{\prime}=\mathrm{CH}_{3}\right)$, respectively.

All catalysts proved to be active to a comparable degree, affording satisfactory conversion values, ranging from 66 to $78 \%$, after only 4 hours (Figure 1). The highest selectivity was observed toward the EP formation, within the range of $49-57 \%$, while PA was obtained in a slightly predominant way over BA (15-22\% vs 10-16\%, respectively, Table 1).

As known, the formation of BA and PA may be normally observed during styrene oxidation, their ratio depending on the specific properties of the catalyst [9a,23]. By prolonging the reaction time up to 8 hours, almost quantitative conversions (83-96\%) were observed, accompanied by an increase in BA yield thus resulting in a consequential reduction (around 15-20\%) of the selectivity toward EP. As a matter of fact, in a control catalytic oxidation performed on styrene oxide, under otherwise identical experimental conditions, a substantial stability of such epoxide toward further oxidation was observed, being the BA formation detectable only in traces. This suggests that the increasing conversion of styrene, upon prolonged reaction times, favors its competitive $\mathrm{C}-\mathrm{C}$ double bond oxidative cleavage, thus lowering the selectivity toward EP in favor of BA formation. On the other hand, this type of selectivity during the catalytic oxidation of styrene, has been commonly observed when working with high valent molybdenum and vanadium based catalysts [23a, 23d].

In addition, after prolonged times, the rate of the catalytic oxidation (promoted by TBHP) considerably 
slows down since an increasing number of tert-butyl alcohol molecules become competitive with TBHP toward the access to the molybdenum center, thus making it more probable the occurrence of side-reactions with recalcitrant substrates [24].

Table 1. Oxidation of styrene with TBHP and catalysts $\mathbf{I}-\mathbf{V} .^{\text {a }}$

\begin{tabular}{|c|c|c|c|c|c|}
\hline Catalyst $^{b}$ & Conv. ${ }^{c} \%$ & & Products $^{\mathrm{d}}$ & & $\mathrm{TON}^{\mathrm{e}}$ \\
\hline & & EP: $\% Y(\% S)^{f}$ & BA: $\% Y(\% S)^{f}$ & PA: $\% Y(\% S)^{f}$ & \\
\hline $\mathbf{I}$ & 83 & $35(56)$ & $12(19)$ & $15(24)$ & 83 \\
\hline II & 88 & $30(50)$ & $10(17)$ & $20(33)$ & 88 \\
\hline III & 89 & $33(50)$ & $11(17)$ & $22(33)$ & 89 \\
\hline IV & 96 & $37(49)$ & $16(21)$ & $22(29)$ & 96 \\
\hline $\mathbf{V}$ & 94 & $39(57)$ & $10(14)$ & $20(29)$ & 94 \\
\hline
\end{tabular}

${ }^{a}$ Exp. conditions: s.m. $(0.2 \mathrm{mmol})$, TBHP (5.5 M in $n$-decane; 2.0 eq.), cat. (1.0 mol\%), $\mathrm{CHCl}_{3}(1.0$ $\mathrm{mL}), 50{ }^{\circ} \mathrm{C}, 8 \mathrm{~h} .{ }^{\mathrm{b}} \mathbf{I}=$ Mo-Met; $\mathbf{I I}=$ Mo-Phe; $\mathbf{I I I}=$ Mo-dmPhe; $\mathbf{I V}=$ Mo-Gly; $\mathbf{V}=$ Mo-Pro. ${ }^{\mathrm{c}} \mathrm{GC}$ yields based on the starting olefin. ${ }^{\mathrm{d}} \mathrm{EP}=$ epoxide; $\mathrm{BA}=$ benzaldehyde; $\mathrm{PA}=$ phenylacetaldehyde. ${ }^{\mathrm{e}} \mathrm{TON}=$ turnover number: $\mathrm{mmol}$ of converted s.m./mmol of catalyst. ${ }^{f} \mathrm{Y}=$ yield and $\mathrm{S}=$ selectivity, after 4 hours.

Substantial differences, in terms of both conversion and yield values, have not been observed among the different catalysts I-V (Figure 1), being catalysts IV and $\mathbf{V}$ only moderately more active. This fact may be tentatively justified on considering that, in the proximity of the catalytic metal center, the different amino acidic side-chain does not strictly affect the formation of active species (i.e. Adduct-1 or Peroxo-2, see onward Figure 5), thus preventing its discriminating role in influencing the selectivity of the oxidation and the stereoselectivity of the epoxide product (see onward).

Blank runs (without catalyst) were performed and, as expected, no significant substrate conversion $(<$ $10 \%$ ) was observed under otherwise similar conditions. 


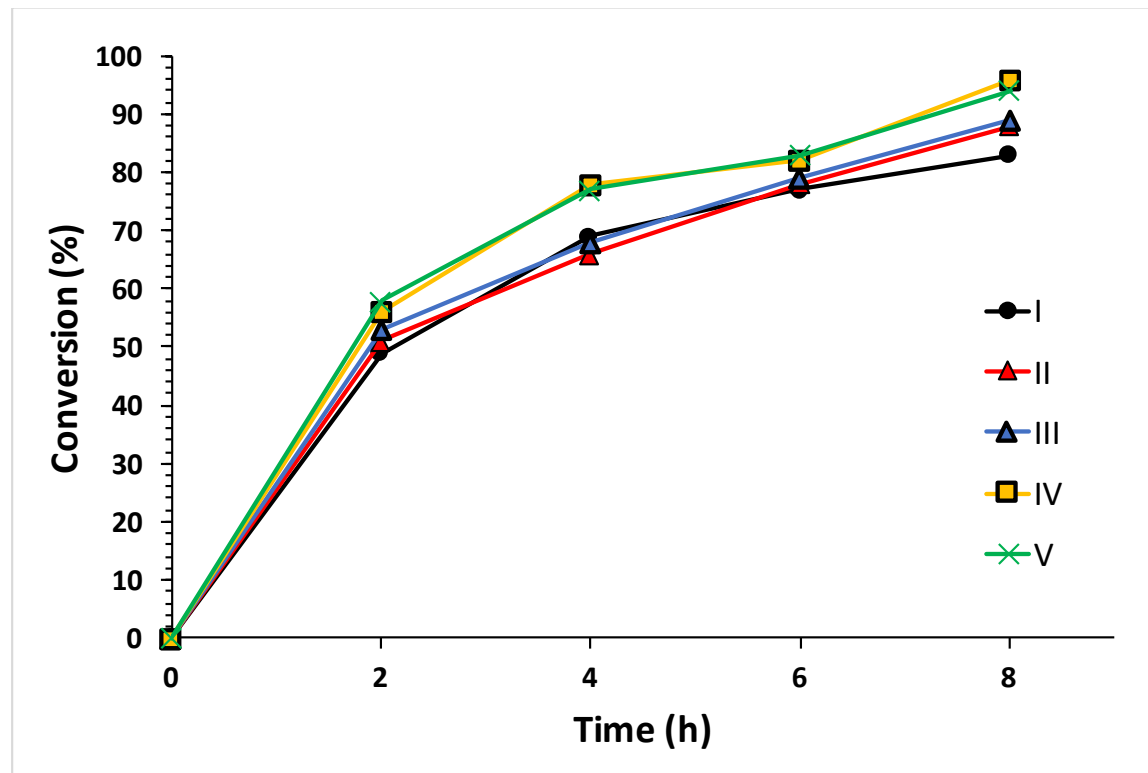

Figure 1. Comparison between catalysts $\mathbf{I}-\mathbf{V}$, in terms of substrate conversion, for the oxidation of styrene with TBHP, after 2, 4, 6 and 8 hours.

\section{Substrate scope and selectivity in the oxidation of other olefins with catalysts $\mathbf{I}-\boldsymbol{V}$}

Encouraged from good results obtained in the oxidation of a reluctant olefin such styrene, we decided to investigate catalysts $\mathbf{I}-\mathbf{V}$ for the selective oxyfunctionalization of $\alpha$ - and $\beta$-methylstyrene (Tables 2 and 3). In the oxidation of $\alpha$-methylstyrene, under optimized conditions, EP and acetophenone (AP, see Chart 2) were the main products, EP being obtained with higher yields (35-48\%, Table 2) with respect to AP (25-30\%, Table 2). As expected, due to the positive role exerted by the methyl group in the alpha position of the double bond (in terms of electron density raising) [23b], the conversion values were higher than those observed with styrene and almost quantitative conversion (89-98\%) was achieved after shorter reaction times (6 vs 8 hours, Table 2). Again, a prolonged reaction time led to a slight reduction of EP yield along with an increase in the AP yield (within the 5-8 \% range of variation). 
Table 2. Oxidation of $\alpha$-methylstyrene with TBHP and catalysts I-V. ${ }^{\text {a }}$

\begin{tabular}{ccccc}
\hline Catalyst $^{\mathrm{b}}$ & Conv. $^{\mathrm{c}} \%$ & \multicolumn{2}{c}{ Products $^{\mathrm{d}}$} & $\mathrm{TON}^{\mathrm{e}}$ \\
\hline & & EP: $\% \mathrm{Y}(\% \mathrm{~S})^{\mathrm{f}}$ & AP: $\% \mathrm{Y}(\% \mathrm{~S})^{\mathrm{f}}$ & \\
\hline I & 98 & $48(62)$ & $30(38)$ & 98 \\
\hline II & 89 & $37(58)$ & $27(42)$ & 89 \\
\hline III & 90 & $35(54)$ & $30(46)$ & 90 \\
\hline IV & 92 & $39(61)$ & $25(39)$ & 92 \\
\hline V & 90 & $38(58)$ & $27(42)$ & 90
\end{tabular}

${ }^{\mathrm{a}}$ Exp. conditions: s.m. (0.2 mmol), TBHP (5.5 M in $n$-decane; 2.0 eq.), cat. (1.0 mol\%), $\mathrm{CHCl}_{3}(1.0 \mathrm{~mL}), 50{ }^{\circ} \mathrm{C}, 6$ h. ${ }^{\mathrm{b}} \mathbf{I}=$ Mo-Met; $\mathbf{I I}=$ Mo-Phe; $\mathbf{I I I}=$ Mo-dmPhe; $\mathbf{I V}=$ Mo-Gly; $\mathbf{V}=$ Mo-Pro. ${ }^{\mathrm{c}} \mathrm{GC}$ yields based on the starting olefin. ${ }^{\mathrm{d}} \mathrm{EP}=$ epoxide; AP $=$ acetophenone. ${ }^{\mathrm{e}} \mathrm{TON}=$ turnover number: $\mathrm{mmol}$ of converted $\mathrm{s} . \mathrm{m} . / \mathrm{mmol}$ of catalyst. ${ }^{\mathrm{f}} \mathrm{Y}=$ yield and $\mathrm{S}=$ selectivity, after 4 hours.

Better results have been obtained from the oxidation of $c$ is- $\beta$-methylstyrene, where almost quantitative conversions (ranging from $90 \%$ up to $98 \%$ ) were observed after shorter reaction times ( 2.5 hours) (Table 3). EP was obtained with high yield and selectivity, while lower yields (8-13\%) were ascertained for BA.

Table 3 Oxidation of $c i s-\beta$-methylstyrene with TBHP and catalysts I-V. ${ }^{\text {a }}$

\begin{tabular}{ccccc}
\hline Catalyst $^{\mathrm{b}}$ & Conv. $^{\mathrm{c}} \%$ & \multicolumn{2}{c}{ Products $^{\mathrm{d}}$} & TON $^{\mathrm{e}}$ \\
\hline I & 96 & $84(88)$ & $12(12)$ & 96 \\
\hline II & 95 & $85(89)$ & $10(11)$ & 95 \\
\hline III & 98 & $90(92)$ & $8(8)$ & 98 \\
\hline IV & 90 & $77(86)$ & $13(14)$ & 90 \\
\hline V & 93 & $82(88)$ & $11(12)$ & 93
\end{tabular}

${ }^{\mathrm{a}}$ Exp. conditions: s.m. (0.2 mmol), TBHP (5.5 M in $n$-decane; 2.0 eq. $)$, cat. (1.0 mol\%), $\mathrm{CHCl}_{3}(1.0 \mathrm{~mL}), 50{ }^{\circ} \mathrm{C}, 2.5 \mathrm{~h}^{\mathrm{b}}{ }^{\mathrm{b}} \mathbf{I}=$ Mo-Met; $\mathbf{I I}=$ Mo-Phe; $\mathbf{I I I}=$ Mo-dmPhe; $\mathbf{I V}=$ MoGly; $\mathbf{V}=$ Mo-Pro. ${ }^{\mathrm{c}} \mathrm{GC}$ yields based on the starting olefin. ${ }^{\mathrm{d}} \mathrm{EP}=$ epoxide; $\mathrm{AP}=$ acetophenone. ${ }^{\mathrm{e}} \mathrm{TON}=$ turnover number: $\mathrm{mmol}$ of converted s.m. $/ \mathrm{mmol}$ of catalyst. ${ }^{\mathrm{f}} \mathrm{Y}=$ yield, $\mathrm{S}=$ selectivity. 
The usual higher reactivity of unconjugated olefins as cyclohexene and cyclooctene toward catalytic oxidation was verified also with our catalysts I-V. Total selectivity toward epoxide formation and quantitative conversions ( $\mathrm{TON}=100)$ were observed with cyclooctene after only 1 hour, while 2 hours were required to obtain the same results with cyclohexene. These results are at all comparable with those previously reported for other types of cis-dioxomolybdenum based catalysts [9a, 25].

Comparative study to evaluate the catalytic activity of I with TBHP or $\mathrm{H}_{2} \mathrm{O}_{2}$

No significative results have been previously observed by us, in chloroform, when $\mathrm{H}_{2} \mathrm{O}_{2}$ was used in the place of TBHP. Therefore, we became interested in evaluating the nature of the interaction between the molybdenum complexes and the two different oxidant species. We decided to investigate, in a comparative study, the behavior of the selected catalyst $\mathbf{I}$ in the presence of a large excess of $\mathrm{H}_{2} \mathrm{O}_{2}$ or TBHP, respectively, under the same conditions used for the catalytic reactions, but without the substrate.

UV-Vis, IR and ${ }^{1}$ H NMR analysis of the chloroform solution showed no evidence for the formation of a soluble molybdenum complex. In fact, in the case of TBHP, a colorless solid deriving from I and dispersed in the aqueous phase was present throughout the experiment. On the other hand, compound I dissolved almost immediately when heated in the presence of $\mathrm{H}_{2} \mathrm{O}_{2}$, with formation of a yellow color in the aqueous phase. According to these observations, it may be concluded that we are dealing with different types of heterogeneous catalytic systems, depending on the selected oxidants: liquid/liquid when using $\mathrm{H}_{2} \mathrm{O}_{2}$ and solid/liquid in the case of TBHP.

At the end of the reaction, a yellow solid was isolated from the aqueous phase containing $\mathrm{H}_{2} \mathrm{O}_{2}$ after solvent evaporation (product I-A), while a white solid (product I-B) was recovered by filtration, in the TBHP experiment (see Schemes 1 and 2). The yellow water-soluble compound I-A was identified by means of IR and NMR spectroscopy. The FT-IR spectrum of this product is very different with respect to that of the starting compound I, displaying bands typical for the stretching of $\mathrm{Mo}=\mathrm{O}\left(960 \mathrm{~cm}^{-1}\right)$, Mo$(\mathrm{O}-\mathrm{O})\left(857 \mathrm{~cm}^{-1}\right)$ and $\mathrm{SO}_{2}\left(1281 \mathrm{~cm}^{-1}, v_{\text {asym }} ; 1127 \mathrm{~cm}^{-1}, v_{\text {sym }}\right)$ moieties (See Figures SI1-SI2 and Table $\mathrm{SI2}$ ). The oxidation of the thioether moiety to sulfone is supported also by ${ }^{13} \mathrm{C}$ NMR data (see Table SI1). An increase in the frequency of the antisymmetric carboxylate stretching and a decrease in the symmetric one was observed on going from I to I-A (Table SI2). A value of $\Delta v=216 \mathrm{~cm}^{-1}$ between these two bands in I-A (instead of $\Delta v=148 \mathrm{~cm}^{-1}$ in $\mathbf{I}$ [15]), suggests a change in the coordination mode of the $\alpha$-amino acid, from bidentate bridging (I) to monodentate (I-A) (Scheme 1) [26a]. 


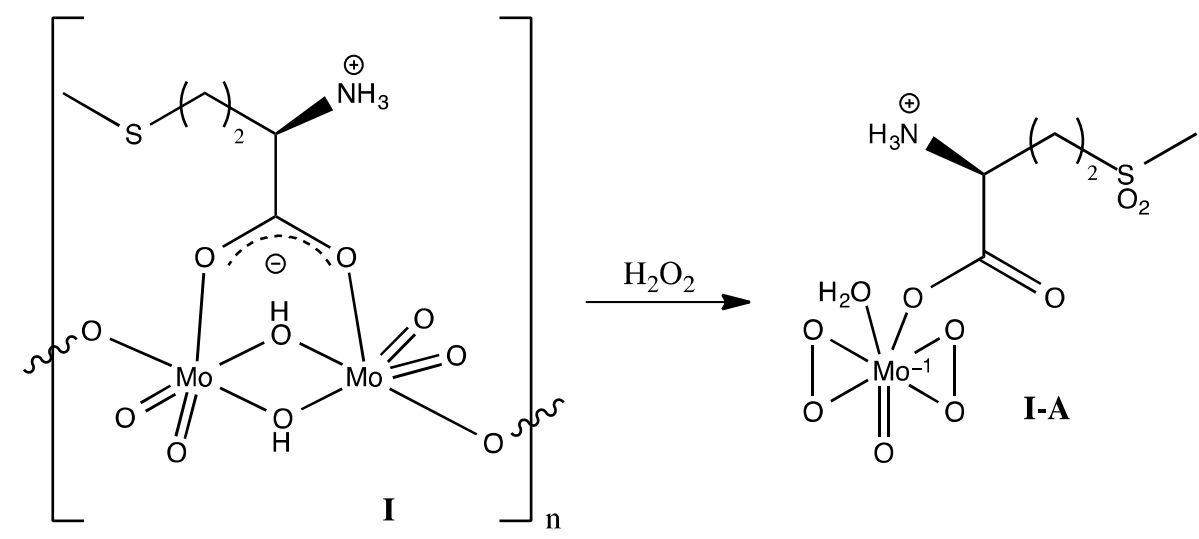

Scheme 1: Sketch of the probable structure of water soluble Mo complex $\left[\mathrm{MoO}\left(\mathrm{O}_{2}\right)_{2}(\mathrm{aaH})\left(\mathrm{H}_{2} \mathrm{O}\right)\right] \mathbf{I}-\mathbf{A}$.

Yellow mononuclear Mo(VI)-oxido/peroxido complexes have already been reported in the literature for a number of $\alpha$-amino acids and their crystal structures are known: they all feature a $\left[\mathrm{MoO}\left(\mathrm{O}_{2}\right)_{2}(\mathrm{aaH})\left(\mathrm{H}_{2} \mathrm{O}\right)\right]$ structure, with a zwitterionic $(\kappa-\mathrm{O})$ monodentate amino acid and two $\eta^{2}$-peroxo ligands [26b]. It is reasonable from IR and NMR data that compound I-A has an analogous $\left[\mathrm{MoO}\left(\mathrm{O}_{2}\right)_{2}(\mathrm{aaH})\left(\mathrm{H}_{2} \mathrm{O}\right)\right]$ structure (Scheme 1). In this respect, further insights have been provided by quantum-chemical calculations (see below).

On the other hand, the white solid quantitatively recovered from the TBHP experiment (I-B) showed an almost identical FT-IR spectrum to the starting compound I (See Figures SI3 and SI4). The appearance of two new weak bands (1125 and 1280-1290 $\left.\mathrm{cm}^{-1}\right)$ indicates the occurrence of thioether to sulfone oxidation within the amino acidic side-chain (Scheme 2 and Table S2). Their low intensity can be justified on considering that only some of the S-Me groups were oxidized. On the other hand, the Mo$\mathrm{O}$ backbone and the amino acid coordination were preserved during the experiment, indicating that the metal center has a much weaker interaction with TBHP than with $\mathrm{H}_{2} \mathrm{O}_{2}$. As a matter of fact, dioxomolybdenum(VI)-alkylperoxo complexes have been observed in solution, but no one of them has been isolated so far [26c-e]. 


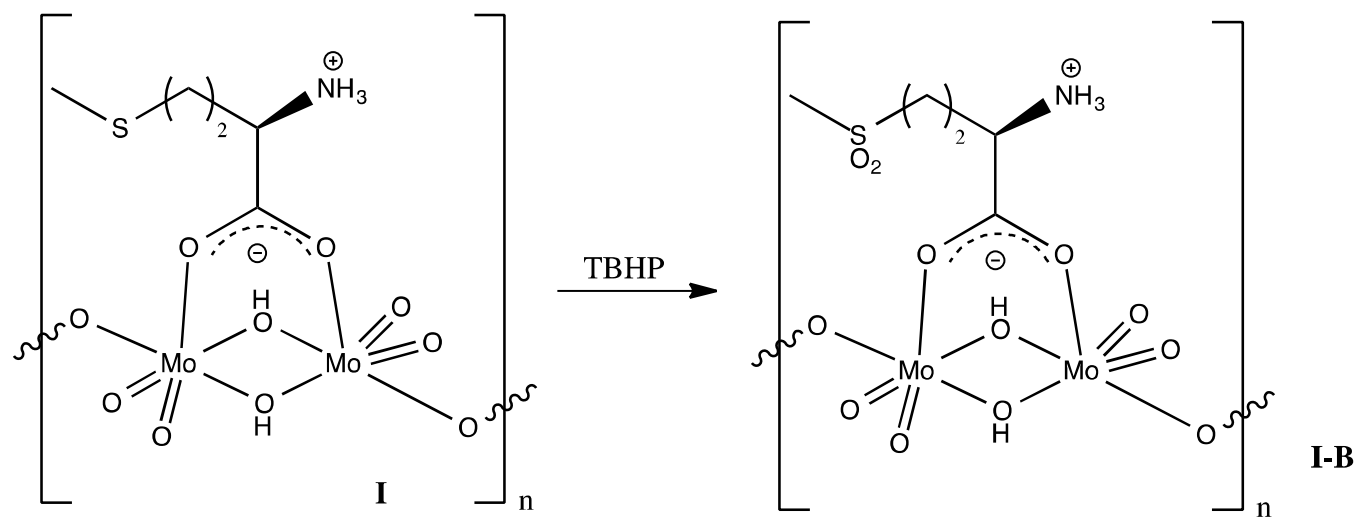

Scheme 2: Sketch of the probable structure of white insoluble Mo complex I-B.

In order to confirm the absence of any catalyst leaching, the solution recovered after filtration of catalyst I (from the above described experiment with TBHP) was checked for activity after addition of fresh reagent (styrene) and TBHP, under the usual conditions, for 3 hours. The absence of activity for the oxidative conversion of styrene (less than $5 \%$ of conversion) after this experiment proved that the catalytic activity stems from the surface-fixed species in a heterogeneous system and not from the leaching of active species into the solution. Moreover, a series of experiments were performed with the selected compound IV in order to evaluate catalyst recyclability in the oxidation of styrene and cyclooctene, under the optimized conditions.

After the first run, the solid recovered and washed with chloroform, was analyzed by FT-IR (KBr disc) to confirm its unmodified nature. We observed that the catalyst recovered after the first cycle continued to be active, under the same conditions, at least for three consecutive cycles, with comparable yield and selectivity values (Table 4).

Table 4. Catalytic recycling experiments with catalyst $\mathbf{I V}^{\mathrm{a}}$

\begin{tabular}{|c|c|c|}
\hline \multirow[t]{2}{*}{ Cycle } & Styrene & Cyclooctene \\
\hline & Conv. \% (Sel. \%) & Conv. \% (Sel. \%) \\
\hline I run & $67(58)$ & $>99(100)$ \\
\hline II run & $65(56)$ & $96(100)$ \\
\hline III run & $62(55)$ & $96(100)$ \\
\hline $\begin{array}{l}\text { onversions } \\
\text { P }\end{array}$ & $\begin{array}{l}\text { as: s.m. }(0.2 \mathrm{mmol}), \mathrm{TBl} \\
\text { ), } \mathrm{CHCl}_{3}(1.0 \mathrm{~mL}), 50 \\
\text { hour for cyclooctene. }\end{array}$ & $\begin{array}{l}5.5 \mathrm{M} \text { in } n \text {-decane; } 2.0 \text { eq } \\
\text { reaction times: } 4 \text { hours f } \\
\text { alyst IV }=\text { Mo-Gly. }{ }^{b} \mathrm{G} \\
\text { electivity values referred }\end{array}$ \\
\hline
\end{tabular}


Finally, the catalysts $\mathbf{I}-\mathbf{V}$ were also studied in order to establish the role, if any, of the $\alpha$-amino acidic ligand, as a chiral inducer, for the formation of the corresponding enantioenriched epoxide, starting from prochiral olefins. In all cases, low enantioselectivity values were detected, for the oxidation of styrene, the best e.e. values ranging from 10 to $13 \%$. This result, could be tentatively explained by supposing that the chiral $\alpha$-amino acid ligand, even if having an important stabilizing effect for the overall stability of compounds $\mathbf{I}-\mathbf{V}$ through the occurrence of an intramolecular H-bond between $-\mathrm{NH}_{3}{ }^{+}$ and (O-O) peroxo moieties (see onward, the Peroxo-2 species in Figures 4 and 5), has the carbon stereocenter lying too far from the catalytically active metal center, thus exercising its role as chiral inducer only to a very small extent.

\section{Results from the computational study}

\section{a) Selection of the model}

The reaction mechanism operative during the oxidation of olefins mediated by dioxomolybdenum(VI) catalysts, using TBHP as main oxidant, is still under study. Even if there is a general accord on the opinion that the catalyst first activates the oxidant molecule followed by oxygen atom transfer to the olefin, there is no uniform agreement on the details of the oxidant activation and oxygen atom transfer. To this scope several detailed theoretical calculations have been published since last decade [21b,27]. As a model system for our calculations, we decided to focus our attention on the oxidation of ethylene, in $\mathrm{CHCl}_{3}$, in the presence of the selected catalyst $\mathbf{I}$, with TBHP or $\mathrm{H}_{2} \mathrm{O}_{2}$ as primary oxidant. The main difficulties associated to the computational elucidation of the catalytic process involving catalyst $\mathbf{I}$ are: (i) the prohibitively large dimension of the system and (ii) the absence of a precise chemical formula due to its polymeric nature. For the first point, we decided to adopt a cluster-based approach, extensively used in this kind of systems [28]; for the second point, inspired by the previous study carried out by some of us [15], we decided to utilize the cis-dioxomolybdenum(VI) octanuclear fragment depicted in Figure 2. 


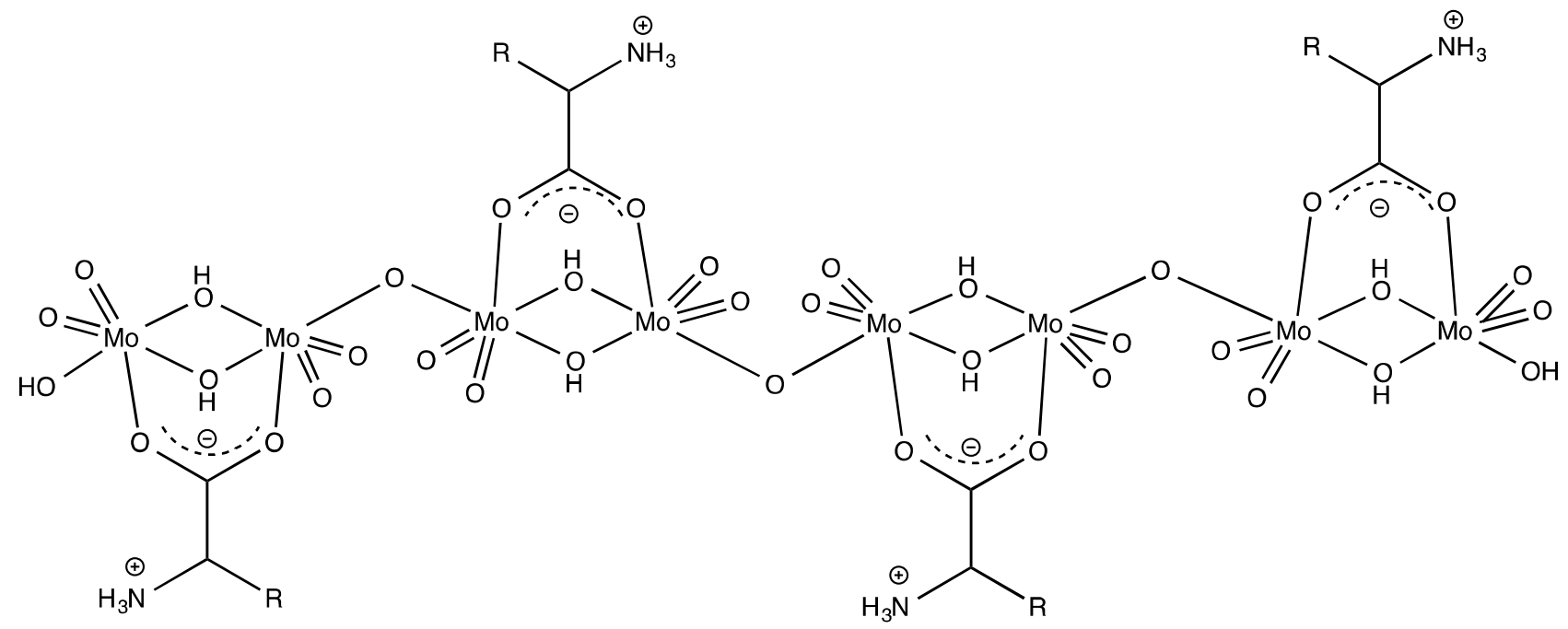

Figure 2. Schematic representation of the octanuclear fragment $\mathrm{HO}-\left(\mathrm{Mo}_{2} \mathrm{O}_{7} \mathrm{H}_{2} \cdot \mathrm{Met}\right)_{4}-\mathrm{H}$ used in the present work for mimicking the catalyst $\mathbf{I}$.

The structure of the polynuclear compound in Figure 2, hereafter termed as $\mathrm{HO}-\left(\mathrm{Mo}_{2} \mathrm{O}_{7} \mathrm{H}_{2} \cdot \mathrm{Met}\right)_{4}-\mathrm{H}$, was obtained in two different computational routes: (i) a Full-Optimization (FO) and (ii) a Constrained-Optimization ( $\mathrm{CO}$ ) in which we maintained rigid the Mo-O framework while relaxing the Methionine moieties.

The calculated IR spectra of CO and FO structures of $\mathrm{HO}-\left(\mathrm{Mo}_{2} \mathrm{O}_{7} \mathrm{H}_{2} \cdot \mathrm{Met}\right)_{4}-\mathrm{H}$, both reported in Figure 3 , essentially differ for the presence of an intense band at $2390 \mathrm{~cm}^{-1}$ (corresponding to a Mo-O-H---O stretching red-shifted because of the occurrence of H-bond) which is absent in the experimental spectrum (Figure SI5). This finding led us to select the CO-based $\mathrm{HO}-\left(\mathrm{Mo}_{2} \mathrm{O}_{7} \mathrm{H}_{2} \cdot \mathrm{Met}\right)_{4}-\mathrm{H}$ as the most plausible structure to be utilized in the modelling of the catalytic mechanism (see below). 


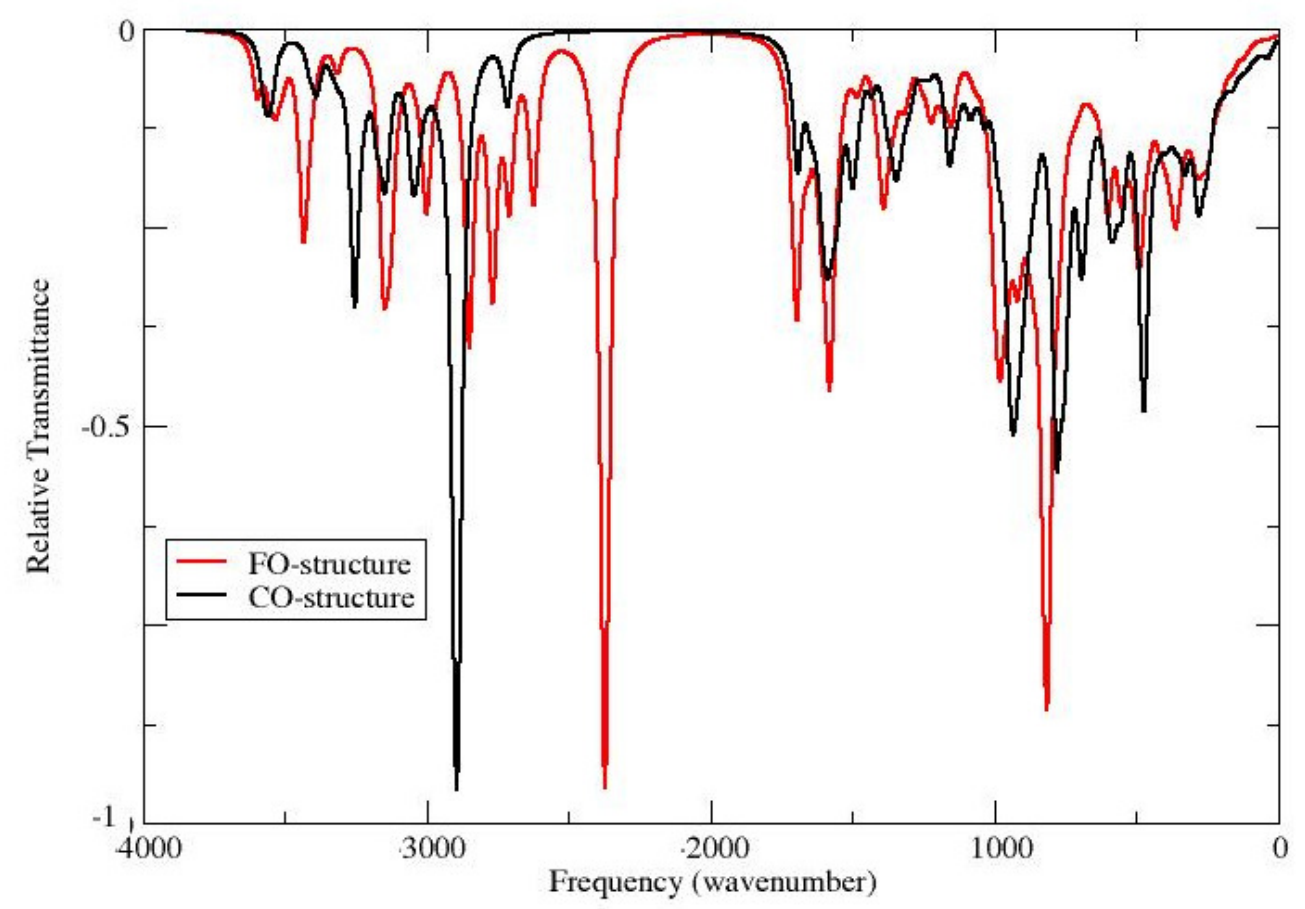

Figure 3. Overlap of the calculated IR spectra for FO (red) and CO (black) of $\mathrm{HO}-\left(\mathrm{Mo}_{2} \mathrm{O}_{7} \mathrm{H}_{2} \cdot \mathrm{Met}\right)_{4}-\mathrm{H}$.

Additional information concerning the IR spectrum calculated for $\mathrm{CO} \mathrm{HO}-\left(\mathrm{Mo}_{2} \mathrm{O}_{7} \mathrm{H}_{2} \cdot \mathrm{Met}\right)_{4}-\mathrm{H}$, are reported in the Supplementary Information (Figure SI6) together with assignment of the most relevant signals, on the basis of the Hessian eigenvectors atomic composition (Table SI3).

Comparison of the calculated spectra with the experimental one, considering all the heavy approximations necessary for the computational modeling, indicates that the selected octanuclear molybdenum model might be utilized for capturing the essential chemical information we are interested in, as below reported.

\section{b) Mechanism of the oxidation of $\mathbf{I}$}

As previously reported, $\mathrm{CO} \mathrm{HO}-\left(\mathrm{Mo}_{2} \mathrm{O}_{7} \mathrm{H}_{2} \cdot \mathrm{Met}\right)_{4}-\mathrm{H}$ has been utilized for modeling the oxidation of $\mathbf{I}$ representing the first step of the catalytic cycle reported in Figure 4. The addition of TBHP $\left(\right.$ or $\left.\mathrm{H}_{2} \mathrm{O}_{2}\right)$ to the starting representative octanuclear molybdenum fragment $\mathrm{HO}-\left(\mathrm{Mo}_{2} \mathrm{O}_{7} \mathrm{H}_{2} \cdot \mathrm{Met}\right)_{4}-\mathrm{H}$ leads to the formation of heptavalent Adduct-1 which, in turns by interaction with ethylene, affords the heptavalent Peroxo-2 intermediate, after the elimination of tert-butanol (or water). Finally, the formation of ethylene oxide regenerates the starting catalytic species (see Figure 4). 


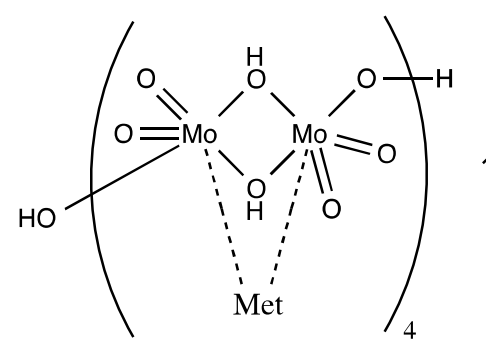

$$
\mathrm{HO}-\left(\mathrm{Mo}_{2} \mathrm{O}_{7} \mathrm{H}_{2} \cdot \mathrm{Met}\right)_{4}-\mathrm{H}
$$

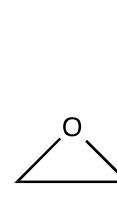

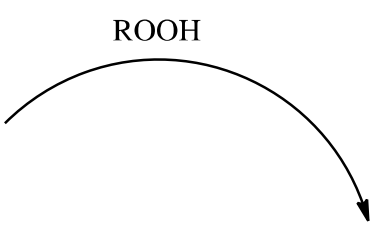

$\mathrm{R}=t \mathrm{Bu}:$ TBHP

$\mathrm{R}=\mathrm{H}: \mathrm{H}_{2} \mathrm{O}_{2}$

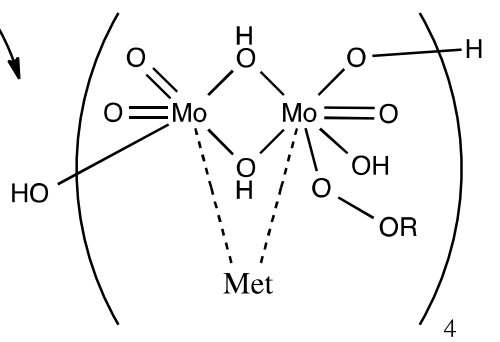

Adduct-1

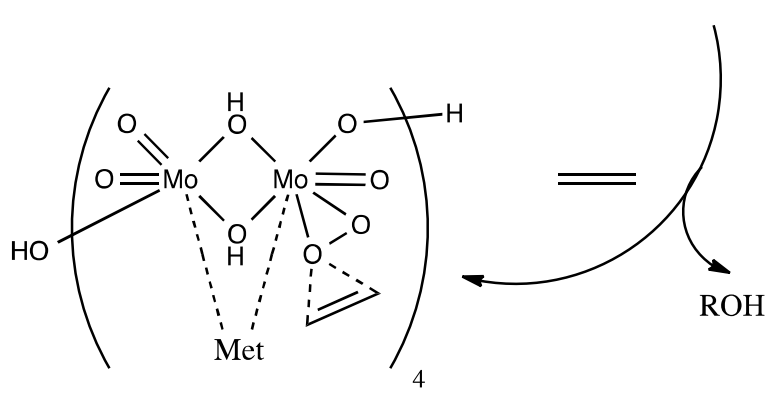

Peroxo-2 and olefin

Figure 4. Schematic representation of the likely catalytic cycle with octanuclear $\mathrm{HO}-\left(\mathrm{Mo}_{2} \mathrm{O}_{7} \mathrm{H}_{2} \cdot \mathrm{Met}\right)_{4^{-}}$ $\mathrm{H}$ model fragment and TBHP $\left(\mathrm{R}=t\right.$-But) or $\mathrm{H}_{2} \mathrm{O}_{2}(\mathrm{R}=\mathrm{H})$.

The full structures of intermediates Adduct-1 and Peroxo- 2 are schematically reported in the Supplementary Information (Figure SI7) together with all the details of the presented structures.

Both TBHP and $\mathrm{H}_{2} \mathrm{O}_{2}$ types of oxidants have been utilized in our model. The schematic representation of the standard free energy diagram at $\mathrm{T}=50{ }^{\circ} \mathrm{C}$ for the formation of the key-intermediate Peroxo- 2 is reported in Figure 5.

Note that, despite several attempts, we were not able to locate a transition structure connecting CO $\mathrm{HO}-\left(\mathrm{Mo}_{2} \mathrm{O}_{7} \mathrm{H}_{2} \cdot \mathrm{Met}\right)_{4}-\mathrm{H}$ and Adduct-1. 


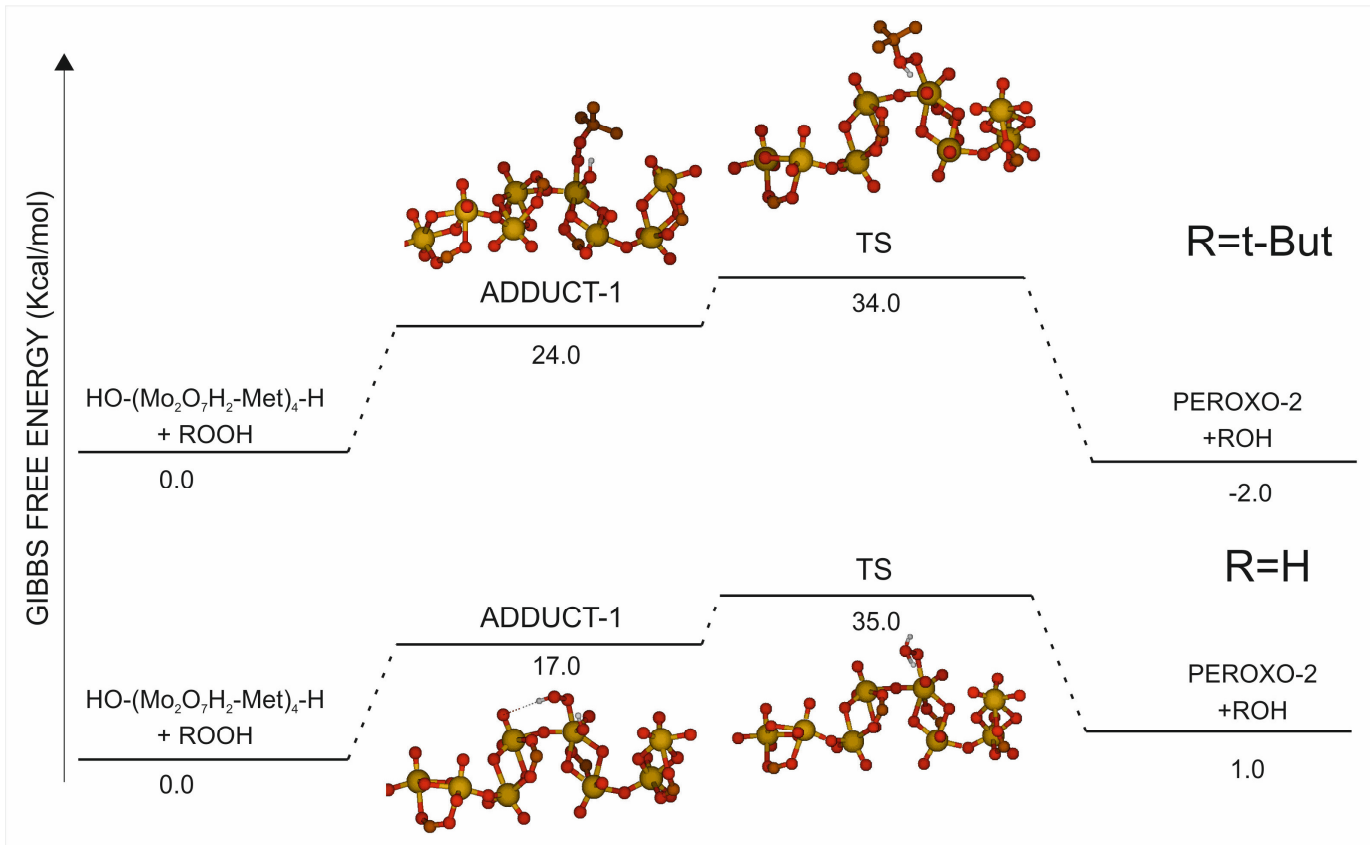

Figure 5. Standard free energy diagram for the formation of Peroxo-2 intermediate with TBHP $(\mathrm{R}=t$ But) and $\mathrm{H}_{2} \mathrm{O}_{2}(\mathrm{R}=\mathrm{H})$, at $50{ }^{\circ} \mathrm{C}$. For sake of clarity, we only reported the carboxyl group of methionine fragment into Adduct-1 and TS structures.

Although alternative mechanisms have been hypothesized in the literature when TBHP is concerned, in the present study we have focused only on the plausible occurrence, if any, of peroxo intermediate in both the investigated reactions (with TBHP or $\mathrm{H}_{2} \mathrm{O}_{2}$ ). In fact, results reported in Figure 5 clearly indicate that not only Peroxo- 2 species is a true minimum on the investigated potential energy surface, but also that its formation, when TBHP is involved, is an exergonic reaction $(-2.0 \mathrm{kcal} / \mathrm{mol}$, corresponding to an equilibrium constant of 22 at $50{ }^{\circ} \mathrm{C}$ ) probably because of the higher ability of $t$-ButOH to behave as leaving group. Diversely, in the case of $\mathrm{H}_{2} \mathrm{O}_{2}$ a slightly endergonic $(1.0 \mathrm{kcal} / \mathrm{mol}$, corresponding to an equilibrium constant of 0.2 at $50{ }^{\circ} \mathrm{C}$ ) reaction was obtained hence indicating that, upon thermodynamic control, TBHP results much more efficient than $\mathrm{H}_{2} \mathrm{O}_{2}$. Thus, if the formation of peroxo species is generally accepted when $\mathrm{H}_{2} \mathrm{O}_{2}$ is used as oxidant, our simulation clearly indicates that also in the case of TBHP its formation cannot be ruled out, at least in the presence of our octanuclear $\mathrm{HO}-\left(\mathrm{Mo}_{2} \mathrm{O}_{7} \mathrm{H}_{2} \cdot \mathrm{Met}\right)_{4}-\mathrm{H}$ model catalyst. 
It is also interesting to remark the role of the amino acidic moiety which, as shown in Figure 6, provides a stabilizing intramolecular $\mathrm{H}$-bond between $-\mathrm{NH}_{3}{ }^{+}$and $(\mathrm{O}-\mathrm{O})$ peroxo moieties probably important for the negative free energy accompanying the elimination of ROH from the Adduct-1 (Fig. 4). This effect is likely to be the most remarkable one played by the amino acidic moiety along the whole process, and may be related to the small enantioselection observed for the formation of epoxide (see above).

Moreover, the barrier for the elimination of the ROH group (indicated as TS in Figure 5), representing the rate determining step of the whole process, appears fairly lower for TBHP probably because of the higher proton affinity of the leaving group $\left(t-\mathrm{BuO}^{-}\right.$vs $\left.\mathrm{HOO}^{-}\right)$. We wish to underline that this latter observation, although apparently able to justify the observed higher efficiency of the reaction when using TBHP, is probably well beyond the chemical accuracy of the theoretical model and the level of calculation.

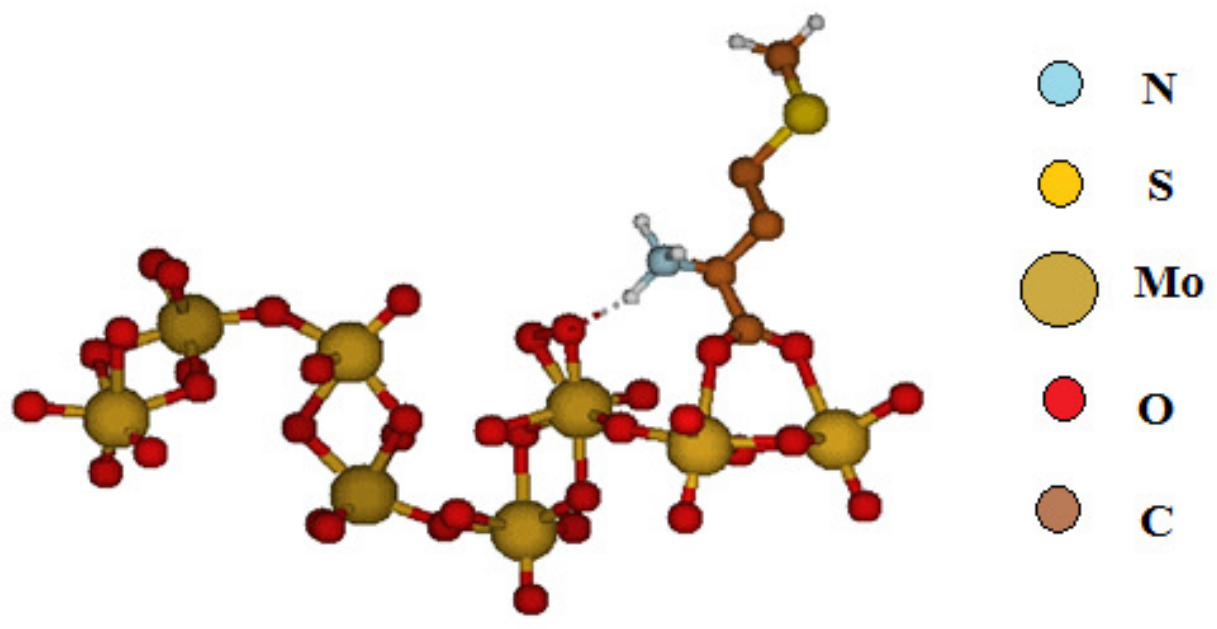

Figure 6. Enlarged view of the intramolecular H-bond as extracted from Peroxo-2 optimized structure. All the hydrogen atoms have been omitted for the sake of clarity.

Briefly, we can summarize that quantum-chemical calculations confirm the presence of stable species resembling the intermediates hypothesized in the catalytic cycle (see Figure 4). At the same time our 
results reveal a possible strategic role of the $\alpha$-amino acid moiety providing the stabilization of the keyintermediate Peroxo-2 through an intramolecular H-bond (Figure 6).

\section{c) Characterization of complex $\boldsymbol{I}-\boldsymbol{A}$}

As a final step of the computational study, we have addressed the structural and spectral analysis of the water-soluble molybdenum complex I-A (see Scheme 1). Moreover, we have also analyzed the kinetic role of I-A with respect to its plausible involvement in the olefin oxidation, in solution. Details of the geometrical features of I-A are reported in the Supplementary Information (see Figures SI1-SI2). The IR spectral features are collected in Figure 7 and in Table 5. Comparison with the relevant experimental IR absorptions found for I-A indicates a good overlap, hence reinforcing the hypothesis about its plausible structure (Scheme 1).

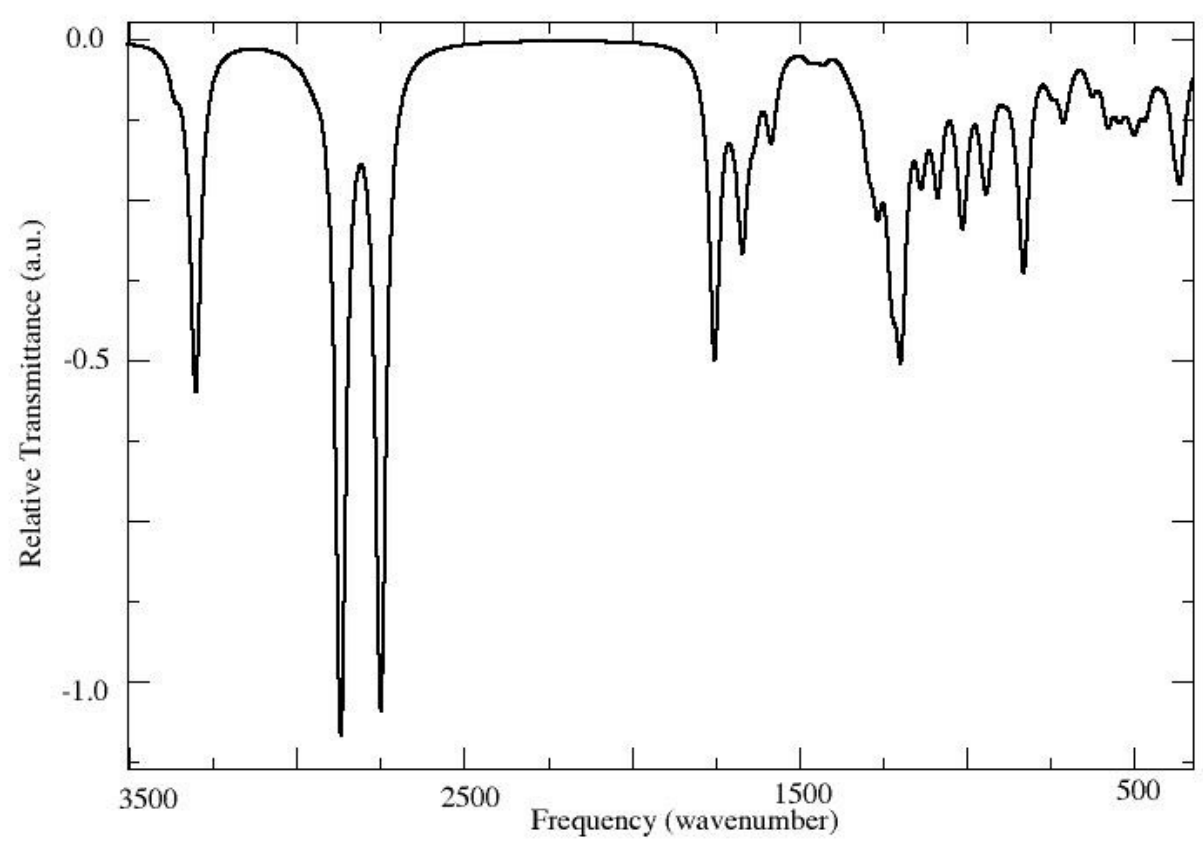

Figure 7. Calculated IR spectrum for I-A species. 
Table 5. Experimental and calculated relevant frequencies and normal modes assignment for I-A species.

\begin{tabular}{|c|c|}
\hline $\begin{array}{l}\text { Experimental Frequencies } \mathrm{cm}^{-1} \\
\text { (assignments) }\end{array}$ & $\begin{array}{l}\text { Calculated Frequencies } \mathrm{cm}^{-1} \\
\text { (assignments) }^{\mathrm{a}}\end{array}$ \\
\hline $3600-3300 \mathrm{~m}-\mathrm{br}[v(\mathrm{OH})]$ & $3335 \mathrm{~s}[\mathrm{v}(\mathrm{OH})]$ \\
\hline $3216-3160 m-b r$ & $2897[v(\mathrm{NH})]$ \\
\hline \multicolumn{2}{|l|}{$3017 \mathrm{~m}$} \\
\hline \multicolumn{2}{|l|}{$2930 \mathrm{~m}$} \\
\hline $1675 \mathrm{~m}-\mathrm{sh}\left[\delta\left(\mathrm{H}_{2} \mathrm{O}\right)\right]$ & $1685\left[\delta\left(\mathrm{H}_{2} \mathrm{O}\right)\right]$ \\
\hline $1621 \mathrm{~m}$ & $1679\left[v\left(\mathrm{CO}_{2}^{-}\right)\right]$ \\
\hline $1506 \mathrm{~m}$ & $1579\left[\delta\left(\mathrm{NH}_{3}\right)\right]$ \\
\hline \multicolumn{2}{|l|}{$1444 \mathrm{~m}-\mathrm{sh}$} \\
\hline $1405 \mathrm{~m}$ & $1481\left[\delta\left(\mathrm{CH}_{2}\right)\right]$ \\
\hline \multicolumn{2}{|l|}{$1369 \mathrm{~m}$} \\
\hline \multicolumn{2}{|l|}{$1323 \mathrm{~m}-\mathrm{sh}$} \\
\hline \multicolumn{2}{|l|}{$1281 \mathrm{~s}\left[v\left(\mathrm{SO}_{2}\right)\right]$} \\
\hline $1193 w$ & $1100\left[v\left(\mathrm{SO}_{2}\right)\right]$ \\
\hline \multicolumn{2}{|l|}{$1127 \mathrm{~s}\left[v\left(\mathrm{SO}_{2}\right)\right]$} \\
\hline \multicolumn{2}{|l|}{$1073 \mathrm{~m}$} \\
\hline $960 \mathrm{~s}[v(\mathrm{Mo}=\mathrm{O})]$ & $1023[v(\mathrm{Mo}=\mathrm{O})]$ \\
\hline $909 w$ & $950[v(\mathrm{O}-\Theta)]$ \\
\hline \multicolumn{2}{|l|}{$857 \mathrm{~s}[v(\mathrm{O}-\Theta)]$} \\
\hline \multicolumn{2}{|l|}{$805 w$} \\
\hline \multicolumn{2}{|l|}{$772 w$} \\
\hline \multicolumn{2}{|l|}{$735 w$} \\
\hline $658 w$ & \\
\hline
\end{tabular}

${ }^{\mathrm{a}}$ Only the most relevant signals have been reported. For the complete spectrum see Figure 7.

We also evaluated the reactivity of $\mathbf{I}-\mathbf{A}$ with ethylene as selected olefin, in $\mathrm{CHCl}_{3}$ solution. To this purpose, we searched for the TS possibly involved in the addition of olefin. The obtained diagram, 
reported in Figure 8, reveals that $\mathbf{I}-\mathbf{A}$ is basically inert with respect to olefin oxidation, thus suggesting a possible explanation of the experimentally observed scarce catalytic activity of I when $\mathrm{H}_{2} \mathrm{O}_{2}$ is employed as oxidant.

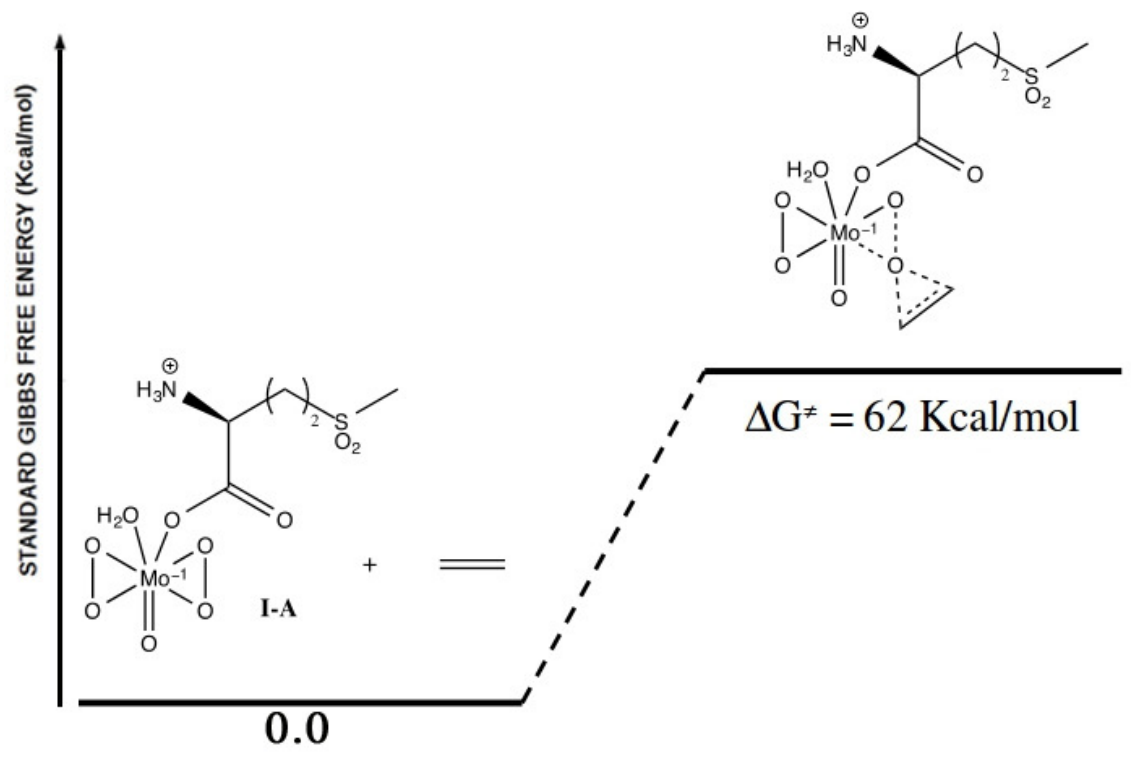

Figure 8. Free energy diagram $\left(50{ }^{\circ} \mathrm{C}\right)$ for the addition of ethene to $\mathbf{I}-\mathbf{A}$ in $\mathrm{CHCl}_{3}$. Details of the calculations are the same as reported in the Experimental Section.

\section{Conclusions}

In this work, the application of a series of cis-dioxomolybdenum(VI)-based compounds I-V containing a chiral bidentate $\alpha$-amino acid donor ligand, as potential catalysts for the selective oxidative functionalization of conjugated or unconjugated olefins (like styrene, $\alpha$-methylstyrene, cis- $\beta$ methylstyrene, cyclohexene and cyclooctene), using tert-butyl hydroperoxide (TBHP) as oxygen source, has been studied. The compounds I-V have proven to be insoluble in the catalytic system when using TBHP as oxidant, confirming that we are dealing with a heterogeneous solid/liquid catalytic process. Their activity in the catalytic oxyfunctionalization of different types of olefins, runs from excellent to very good levels if we move from unconjugated olefins as cyclohexene and cyclooctene toward the less reactive styrene, always showing higher selectivity over the corresponding epoxides.

The absence of relevant differences in terms of both conversion of substrates and product yields among the different catalysts $\mathbf{I}-\mathbf{V}$, suggests that, in the proximity of the catalytic metal center, the variable amino acidic side-chain, does not strictly affect the activation process, thus preventing a possible discriminant role in the selectivity of the oxidation, including the stereoselectivity of the epoxide 
product. Nevertheless, a possible active role of the amino acidic moiety in the stabilization of the key intermediate through an intramolecular hydrogen bond, as suggested from quantum-chemical calculations, cannot be ruled out. Interestingly, the catalyst IV showed to be recyclable (at least for three consecutive cycles), during the oxidation of styrene and cyclooctene, as representative substrates. Quantum-chemical calculations, carried out on a model system whose reliability has been based by comparing the related IR spectrum with the experimental one, have given insights into the structure and energetic of the intermediates possibly involved in the catalytic route.

On the other hand, when $\mathrm{H}_{2} \mathrm{O}_{2}$ was employed as the oxidant, a soluble Mo-peroxido species I-A was isolated and characterized by IR/NMR spectroscopy and DFT calculations. These last, carried out at the same level of theory, indicate that such species I-A is scarcely reactive towards ethylene epoxydation, thus confirming the experimentally observed absence of catalytic activity with compounds I-V in the presence of $\mathrm{H}_{2} \mathrm{O}_{2}$.

In our opinion, this study confirms the remarkable catalytic potential of Mo(VI) systems as valid candidates for sustainable processes, shedding light on a topic that, while covering a considerable synthetic interest [29], has been poorly studied from the point of view of its application in heterogeneous oxidative catalysis [30].

\section{Supporting Information}

Comparison of IR spectra of compounds I, I-A and I-B and of ${ }^{13} \mathrm{C}$ NMR data of compounds I, I-A and related species; IR spectrum of I; calculated IR spectrum and selected frequencies, normal modes assignment for $\mathrm{CO} \mathrm{HO}-\left(\mathrm{Mo}_{2} \mathrm{O}_{7} \mathrm{H}_{2} \cdot \mathrm{Met}\right)_{4}-\mathrm{H}$ and comparison with experimental IR values for $\mathbf{I}$. Schematic representation of the proposed intermediates Adduct-1 and Peroxo-2, for the catalytic cycle model. Experimental details related to the behavior of I-A in aqueous solution, and for the preparation of L-methionine sulfoxide and sulfone. Details of quantum chemical calculated structures.

\section{Acknowledgements}

The Universities of Pisa and L'Aquila are gratefully acknowledged for financial support. I.A. thanks to the Phoenix Study Programme (PX14DF0786 code) for his PhD scholarship.

\section{References}

[1] E. I. Stiefel, Met. Ions Biol. Syst. 39 (2002) 1-29.

[2] R. R. Mendel, Dalton Trans. (2005) 3404-3409. 
[3] (a) A. Majumdar, S. Sarkar, Coord. Chem. Rev. 255 (2011) 1039-1054;

(b) R. H. Holm, E. I. Solomon, A. Majumdar, A. Tenderholt, Coord. Chem. Rev. 255 (2011) 9931015 ;

(c) S. Metz, W. Thiel, Coord. Chem. Rev. 255 (2011) 1085-1103.

[4] R. H. Holm, Chem. Rev. 87 (1987) 1401-1449.

[5] A. Patel, S. Pathan, Ind. Eng. Chem. Res. 51 (2012) 732-740.

[6] L. Shechter, J. Wynstra and R. Kurkjy, Ind. Eng. Chem. 49 (1957) 1107-1109.

[7] (a) M. Amini, M. M. Haghdoost, M. Bagherzadeh, Coord. Chem. Rev. 257 (2013) 1093-1121;

(b) K. C. Gupta, A. K. Sutar and C. C. Lin, Coord. Chem. Rev., 253 (2009) 1926-1946;

(c) K. C. Gupta, A. K. Sutar, Coord. Chem. Rev. 252 (2008) 1420-1450;

(d) S. Liu, J. Xiao, J. Mol. Catal. A 270 (2007) 1-43;

(e) Q.-H. Xia, H.-Q. Ge, C.-P. Ye, Z.-M. Liu and K.-X. Su, Chem. Rev. 105 (2005) 1603-1662;

(f) B. S. Lane, K. Burgess, Chem. Rev. 103 (2003) 2457-2474;

(g) C.-M. Che and J.-S. Huang, Coord. Chem. Rev. 242 (2003) 97-113;

(h) D. Sherrington, Catal. Today 57 (2000) 87-104;

(i) M. H. Dickman, M. T. Pope, Chem. Rev. 94 (1994) 569-584;

(j) K. A. Jørgensen, Chem. Rev. 89 (1989) 431-458.

[8] H. Noh, Y. Cui, A. W. Peters, D. R. Pahls, M. A. Ortuño, N. A. Vermeulen, C. J. Cramer, L. Gagliardi, J. T. Hupp, O. K. Farha, J. Am. Chem. Soc. 138 (2016) 14720-14726.

[9] (a) J. A. Schachner, P. Traar, C. Sala, M. Melcher, B. N. Harum, A. F. Sax, M. Volpe, F. Belaj, N.

C. Mösch-Zanetti, Inorg. Chem. 51 (2012) 7642-7649;

(b) K. Jeyakumar, D. K. Chand, Synthesis (2008) 807-819.

[10] (a) M. E. Judmaier, C. Holzer, M. Volpe and N. C. Mösch-Zanetti, Inorg. Chem. 51 (2012) 99569966;

(b) P. Neves, S. Gago, C. Pereira, S. Figueiredo, A. Lemos, A. Lopes, I. Gonçalves, M. Pillinger,

C. Silva and A. Valente, Catal. Lett. 132 (2009) 94-103;

(c) S. M. Bruno, S. S. Balula, A. A. Valente, F. A. Almeida Paz, M. Pillinger, C. Sousa, J.

Klinowski, C. Freire, P. Ribeiro-Claro, I. S. Gonçalves, J. Mol. Catal. A 270 (2007) 185-194;

(d) M. Abrantes, A. M. Santos, J. Mink, F. E. Kühn, C. C. Romão, Organometallics 22 (2003) 2112-2118.

[11] (a) M. Bortoluzzi, M. Hayatifar, F. Marchetti, G. Pampaloni, S. Zacchini, Inorg. Chem. 54 (2015) 4047-4055 
(b) K. Vassilev, M. Dimitrova, S. Turmanova and R. Milina, Synth. React. Inorg. Met.-Org. Chem., 43 (2013) 243-249;

(c) W. J. Shaw, Catal. Rev. Sci. Eng. 54 (2012) 489-550;

(d) D. Desbouis, I. P. Troitsky, M. J. Belousoff, L. Spiccia, B. Graham, Coord. Chem. Rev., 256 (2012) 897-937;

(e) K. Micskei, T. Patonay, L. Caglioti, G. Palyi, Chem. Biodiversity 7 (2010) 1660-1669;

(f) K. Severin, R. Bergs, W. Beck, Angew. Chem., Int. Ed. 37 (1998) 1635-1654.

[12] M. Tašner, B. Prugovecki, Z. Soldin, S. Prugovecki, L. Rukavina, D. Matkovic-Calogovic, Polyhedron 52 (2013) 268-275, and literature cited therein.

[13] See for instance: (a) W. S. Zhu, H. Li, Q. Q. Gu, P. Wu, G. Zhu, Y. Yan and G. J. Chen, J. Mol. Catal. A 336 (2011) 16-22;

(b) M. L. Ramos, L. L. G. Justino and H. D. Barroiws, Dalton Trans. 40 (2011) 4374-4383;

(c) E. Cartuyvels, K. Van Hecke, L. Van Meervelt, C. Görller-Walrand, T. N. Parac-Vogt, J. Inorg. Biochem. 102 (2008) 1589-1598;

(d) U. Kortz, J. Vaissermann, R. Thouvenot, P. Gouzerh, Inorg. Chem. 42 (2003) 1135-1139;

(e) U. Kortz, M. G. Savelieff, F. Y. A. Ghali, L. M. Khalil, S. A. Maalouf, D. I. Sinno, Angew. Chem., Int. Ed. 41 (2002) 4070-4073.

[14] K. Vassilev, S. Turmanova, E. Ivanova, V. Trifonova, J. Biomater. Nanobiotechnol. 4 (2013) 2836.

[15] L. Biancalana, M. Bortoluzzi, C. Forte, F. Marchetti, G. Pampaloni, RSC Adv. 5 (2015) 90109018.

[16] (a) The ${ }^{1} \mathrm{H}$ NMR signal of $\mathrm{H}_{2} \mathrm{O}_{2}$ is concentration-dependent: N. A. Stephenson, A. T. Bell, Anal. Bioanal. Chem. 381 (2005) 1289-1293.

(b) M. J. Frisch et al. Gaussian, Inc., Wallingford CT, 2013.

[17] J. Tomasi, B. Mennucci, R. Cammi, Chem. Rev. 105 (2005) 2999-3093.

[18] T. Yanai, D. Tew, N. Handy, Chem. Phys. Lett. 393 (2004) 51-57.

[19] P. J. Hay and W. R. Wadt, J. Chem. Phys. 82 (1985) 299-310.

[20] (a) F. E. Kuhn, M. Groarke, E. Bencze, E. Herdtweck, A. Prazeres, A. M. Santos, M. J. Calhorda, C. C. Romao, I. S. Goncalves, A. D. Lopes, M. Pillinger, Chem. Eur. J. 8 (2002) 2370-2383;

(b) M. Minelli, J.H. Enemark, R.T.C. Brownlee, M.J. O’Connor, A.G. Wedd, Coord. Chem. Rev. 68 (1985) 169-278.

[21] (a) M. Cindric, G. Pavlovic, R. Katava, D. Agustin, New J. Chem. 41 (2017) 594-602; 
(b) J. Morlot, N. Uyttebroeck, D. Agustin, R. Poli, ChemCatChem 5 (2013) 601-611.

[22] (a) M. Bagherzadeh, R. Latifi, L. Tahsini, V. Amani, A. Ellern, L. K. Woo, Polyhedron 28 (2009) 2517-2521;

(b) Rezaeifard, A.; Sheikhshoaie, I.; Monadi, N.; Stoeckli-Evans, H. Eur. J. Inorg. Chem. 2010 (2010) 799-806.

[23] (a) G. Romanowski, J. Kira, Polyhedron, 117 (2016) 352-358;

(b) S. Rayati, N. Rafiee, A. Wojtczak, Inorg. Chim. Acta, 386 (2012) 27-35;

(c) J. Valand, H. Parekh, H. B. Friedrich, Catalysis Communications 40 (2013) 149153 ;

(d) F. Marchetti, C. Pettinari, C. Di Nicola, R. Pettinari, A. Crispini, M. Crucianelli, A. Di Giuseppe, Appl. Catal. A 378 (2010) 211-220.

[24] J. Zhao, X. Zhou, A. M. Santos, E. Herdtweck, C. C. Romão, F. E. Kühn, Dalton Trans. (2003) 3736-3742.

[25] M. Bagherzadeh, L. Tahsini, R. Latifi, L. K. Woo, Inorg. Chim. Acta 362 (2009) 36983702.

[26] (a) G. B. Deacon, R. J. Phillips, Coord. Chem. Rev. 33 (1980) 227-250:

(b) C. Djordjevic, N. Vuletic, B. A. Jacobs, M. Lee-Renslo, E. Sinn, Inorg. Chem. 36 (1997) 1798-1805.

(c) E.P. Talsi, O. V. Klimov, Z. I. Zamaraev, J. Mol. Catal. 83 (1993) 329-346;

(d) M. Groarke, I. S. Gonçalves, W. A. Herrmann, F. E. Kühn, J. Organomet. Chem. 649 (2002) 108-112;

(e) C. Bhaumik, E. Manoury, J.-C. Daran, P. Sözen-Aktas, F. Demirhan, R. Poli J. Organomet. Chem. 760 (2014) 115-123.

[27] (a) L. F. Veiros, A. Prazeres, P. J. Costa, C. C. Romão, F. E. Kühn, M. J. Calhorda, Dalton Trans., (2006) 1383-1389;

(b) P. J. Costa, M. J. Calhorda, F. E. Kühn, Organometallics, 29 (2010) 303-311.

(c) A. Comas-Vives, A. Lledós, R. Poli, Chem. Eur. J., 16 (2010) 2147 -2158.

[28] H. Noh, Y. Cui, A. W. Peters, D. R. Pahls, M. A. Ortuño, N. A. Vermeulen, C. J. Cramer, L.

Gagliardi, J. T. Hupp, O. K. Farha, J. Am. Chem. Soc. 138 (2016) 14720-14726.

[29] (a) S.-M. Chen, C.-Z. Lu, Y.-Q. Yu, Q.-Z. Zhang, X. He, Acta Cryst. C60 (2004) m437-m439;

(b) T. Yamase, M. Inoue, H. Naruke, K. Fukaya, Chem. Lett. (1999) 563-564.

[30] M. Najafi, A. Abbasi, M. Masteri-Farahani, H. Shahbaazi, M. Ahmadniai Motlaghd, J. Janczak, 
RSC Adv. 6 (2016) 29944-29949. 